\title{
Electronic Properties of Boron and Silicon Doped (10, 0) Zigzag Single-Walled Carbon Nanotube upon Gas Molecular Adsorption: A DFT Comparative Study
}

\author{
P. A. Gowri sankar and K. Udhayakumar \\ Department of Electrical Engineering, Anna University, Chennai 600025, India \\ Correspondence should be addressed to P. A. Gowri sankar; gowrisankar_eee@yahoo.co.in
}

Received 26 September 2013; Revised 10 December 2013; Accepted 12 December 2013

Academic Editor: Takuya Tsuzuki

Copyright (C) 2013 P. A. Gowri sankar and K. Udhayakumar. This is an open access article distributed under the Creative Commons Attribution License, which permits unrestricted use, distribution, and reproduction in any medium, provided the original work is properly cited.

\begin{abstract}
We have performed a comparative study of nine predominant gas molecules $\left(\mathrm{H}_{2}, \mathrm{H}_{2} \mathrm{O}, \mathrm{O}_{2}, \mathrm{CO}, \mathrm{CO}_{2}, \mathrm{NO}, \mathrm{NO}_{2}, \mathrm{NH}_{3}\right.$, and $\left.\mathrm{CH}_{3} \mathrm{OH}\right)$ adsorption property on the top surface of the $(10,0)$ zigzag single-walled pristine Carbon nanotube (C-CNT), Boron doped carbon nanotube (B-CNT), and Silicon doped carbon nanotube (Si-CNT) are investigated by using density functional theory (DFT) computations to exploit their potential applications as gas sensors. For the first time, we calculated the optimal equilibrium position, absorption energy $\left(E_{\mathrm{ad}}\right)$, and density of states (DOS) of the considered gas molecules adsorbed on the open end of zigzag singlewalled $(10,0) \mathrm{B}-\mathrm{CNT}$ and Si-CNT. Our first principle calculations demonstrate that the B-CNT and Si-CNT adsorbent materials are able to adsorb the considered gas molecules with variety of adsorption energy and their electronic structure dramatic changes in the density of states near the Fermi level. The obtained comparative DFT studies results are useful for designing a high-fidelity gas sensor materials and selective adsorbents for a selective gas sensor.
\end{abstract}

\section{Introduction}

Gas molecular adsorption in nanostructures is an important issue for both fundamental research and technical application. In recent years, carbon nanotubes have been intensively studied due to their importance as building blocks in nanotechnology. The special geometry and unique properties of carbon nanotubes offer great potential applications, such as nanoelectronic devices, fuel cell, energy storage, chemical probes and biosensors, field emission display, and gas sensor [1-4]. Carbon nanotubes (CNTs) have the potential to be developed as a new gas sensing material due to their inherent properties such as their small size, great strength, high electrical and thermal conductivity, high surface-to-volume ratio, and hollow structure of nanomaterials. As a result, it is possible to create a miniaturized sensor, which can lead to low power consumption, lighter, and low cost. Therefore, CNTsbased gas sensors and their mechanisms have been widely studied recently. Different kinds of nanotubes have been investigated for gas molecules adsorption, such as carbon nanotubes (CNTs) [5-15], boron nitride nanotubes (BNNTs)
[16-22], boron doped nanotubes [23-27], silicon carbide nanotubes [28-46], zinc oxide nanotube, $\mathrm{TiO}_{2}$ nanotube, tungsten carbide nanotube, and $\mathrm{MgO}$ nanotube [47]. Meanwhile, the efficiency of gas adsorption on pristine carbon nanotubes can be enhanced by doping process [16-46].

Doping (heteroatom substitution) is also a promising approach to enable single-walled carbon nanotubes (SWCNTs) to detect gas molecules as well as organic chemicals and biological substances, since the adsorption capability of SWCNTs can be improved through introducing heteroatom impurities (such as boron, nitrogen, silicon, zinc, and titanium) and forming active sites in tube walls. In the literature, a lot of papers briefly discussed gas molecules adsorption property of boron doped carbon nanotube and nitrogen doped carbon nanotube. Further, the potential of silicon doped carbon nanotube (Silicon carbide nanotube) gas molecules adsorption property has to be investigate for various small gases such as $\mathrm{H}_{2}, \mathrm{H}_{2} \mathrm{O}, \mathrm{O}_{2}, \mathrm{CO}, \mathrm{CO}_{2}, \mathrm{NO}$, $\mathrm{NO}_{2}, \mathrm{NH}_{3}$, and $\mathrm{CH}_{3} \mathrm{OH}$. The recently synthesized silicon carbide $(\mathrm{SiC})$ nanotube $[44,45]$ has been found to be a semiconducting material and is of great technological interest 


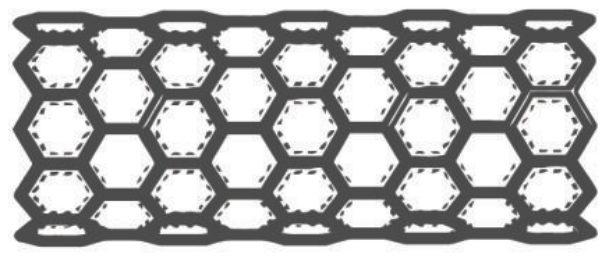

(a)

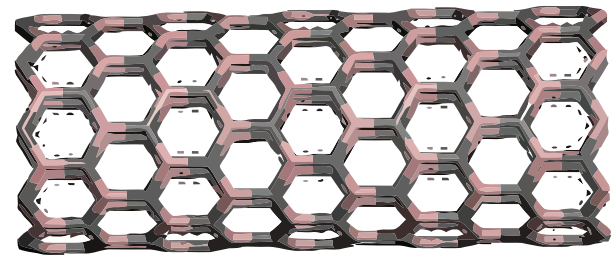

(b)

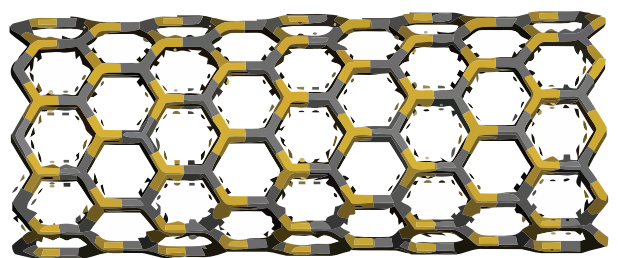

(c)

Figure 1: Gas molecules adsorbents model (a) (10, 0) zigzag single-walled Pristine Carbon nanotube, (b) (10, 0) zigzag single-walled Boron doped carbon nanotube (B-CNT), and (c) $(10,0)$ zigzag single-walled silicon doped carbon nanotube (Si-CNT).

for devices designed to operate at high temperatures, high power, and in harsh environments. An attractive point is that $\mathrm{SiC}$ nanotube has higher reactivity than carbon nanotube (CNT) or boron nitride nanotube (BNNT) due to its great polarity $[42,43]$. Obviously, these unique properties of $\mathrm{SiC}$ nanotube are the key advantages for its applications to the building blocks in the fabrication of electronic nanodevices and chemical adsorbents.

Exploring the electronic properties of $\mathrm{SiC}$ nanotubes upon considered gas molecule absorption condition is very helpful for widening their practical applications such as gas sensor, and many routes have been addressed to evaluate the changes of their properties. Very recently, Gao et al. investigated theoretically the interaction between $\mathrm{NO}_{2}$ molecule and $\mathrm{SiC}$ nanotube [35]. They reported that a single $\mathrm{NO}_{2}$ molecule can be chemically adsorbed on the outer surface of $\mathrm{SiC}$ nanotube with a relatively large adsorption energy $(\sim 1.0 \mathrm{eV})$, and the electronic properties are modified by the $\mathrm{NO}_{2}$ adsorption. Followed by $\mathrm{CO}, \mathrm{NO}$, and $\mathrm{O}_{2}$, gas molecules adsorption property on silicon carbide nanotube is investigated theoretically by [30-46]. However, to our knowledge, no experimental or theoretical investigation has been reported on the adsorption of $\mathrm{H}_{2}, \mathrm{H}_{2} \mathrm{O}, \mathrm{CO}, \mathrm{NH}_{3}$, and $\mathrm{CH}_{3} \mathrm{OH}$ on the surfaces of silicon doped carbon nanotube (Si-CNT). Such a study has been done in this paper.

In this paper, we focus on the interaction behavior of important classes of molecules $\left(\mathrm{H}_{2}, \mathrm{H}_{2} \mathrm{O}, \mathrm{O}_{2}, \mathrm{CO}, \mathrm{CO}_{2}\right.$, $\mathrm{NO}, \mathrm{NO}_{2}, \mathrm{NH}_{3}$, and $\mathrm{CH}_{3} \mathrm{OH}$ ) with C-CNT, B-CNT and SiCNT being studied extensively by DFT method. The overall aim of this study is to provide the fundamental insight into the molecular interactions between these common gaseous and our proposed adsorbates B-CNT and Si-CNT models. The adsorption energy $\left(E_{\text {ad }}\right)$, binding distance $(\mathrm{BD})$, and electronic structure of the considered gas molecular species are calculated. This information is ultimately necessary for the molecular design of new adsorbents and sensing materials. Our first-principle calculations demonstrate that the proposed models of B-CNT and Si-CNT exhibit a variety of adsorption interactions and their electronic structure dramatic changes in the density of states near the Fermi level with the considered gas molecule being probed. This information can be used to guide experimental synthesis, depending upon the requirements of the specific gas sensor application.

\section{Computational Methods}

In the present work, adsorption behaviors of the nine predominate gas molecules are studied by using the C-CNT, BCNT and Si-CNT, representative models of open edge (10, 0 ) zigzag single-walled nanotubes (SWNTs) with optimized molecular orientations. A primary $(10,0) \mathrm{C}-\mathrm{CNT}$ containing 160 carbon atoms with length of $17.04 \AA$ is chosen for the purpose. Since the exact distribution of boron atoms on the nanotube was still unknown, for the B-CNT $(10,0)$ structure, we distributed ten carbon atoms in the primary C-CNT (10, 0 ) supercell which were substituted by B atoms with only one constraint: boron atoms could not occupy the positions of their nearest neighbors on the hexagonal carbon structure. The structural verification and stability of the B-CNT $(10,0)$ models employed in this work have been described elsewhere [23-27]. The Si-CNT $(10,0)$ structure also constructed C80Si80 atomic configuration in a supercell. The adsorbents nanotube models are shown in Figures 1(a), 1(b), and 1(c), respectively. One-dimensional periodic boundary condition are applied along the tube axis. The number of carbon layers along the tube axis is chosen such that the absolute value for the total charge approaches zero and the total energy do not change as the number of layers increased. For all the tubes, one gas molecule per unit cell is considered in the tube axis direction. Density functional theory (DFT) has been extensively used for the calculation of adsorption energy and density of states (DOS) properties of individual pristine carbon nanotube (C-CNT), boron doped carbon nanotube (B-CNT), and silicon doped carbon nanotube (Si-CNT) on gas adsorption. The self-consistent field (SCF) electronic structure calculations are performed based on density functional theory 
(DFT) with either localized basis (DMol) or plane-wave basis (CASTEP) [48]. The equilibrium geometry and adsorption energy are calculated by using the DMol program. The density functional is treated by the local density approximation (LDA) with exchange-correlation potential parameterized by [48]. The energy cutoff of the plane wave basis is chosen up to $760 \mathrm{eV}$. In this paper, we find out that the optimum adsorbates orientation, and optimum binding distance have been attempted in order to locate the lowest energy configuration of the adsorbate + tube system. The adsorption energy $\left(E_{\mathrm{ad}}\right)$ is defined as the difference between the energy of the SWCNT + molecule(s) system, minus the sum of the energies of the SWCNT and of the isolated molecule(s) in the same conditions. (Supercell size, $k$-points, etc.). Negative values of $E_{\text {ad }}$ denote an exothermic adsorption process. We calculated adsorption energy (binding energy) of the system as a function of the distance between the gas molecule and the surface of the wall for various orientations. The adsorption energy $E_{\mathrm{ad}}$ is calculated according to the expression (1) as follows:

$$
E_{\text {ad }}=\left(E_{\text {tube }}+E_{\text {gas }}\right)-E_{\text {tube-gas }} .
$$

It should be noted that calculation of the charge on atoms is quite difficult. However, the charge transfer between the molecule and the nanotube is calculated from the charge difference of each atom before and after molecule absorption, which should be independent of the method used, although, in practice, some minor deviations may exist.

\section{Results and Discussions}

It is essential to understand the adsorption behavior of several potentially-important molecular species. Thus, the adsorption energy $\left(E_{\mathrm{ad}}\right)$, binding distance (BD), electronic band structure, and density-of-states (DOS) of the considered gas molecular species are calculated, and this information can be used to clearly define the adsorption nature of these molecules on the C-CNT, B-CNT, and Si-CNT adsorbents material. The most stable configurations for the gas adsorbates based on Si-CNT (our choice of interested adsorbent model) are displayed in Figure 2. Like that, the most stable configurations for the gas adsorbates based on B-CNT are also chosen for our calculation, which is not shown here. The represented silicon carbide nanotube model consist of $\mathrm{Si}$ and $\mathrm{C}$ atomic structure. The calculated average $\mathrm{Si}-\mathrm{C}$ bond length of these tubes is about $1.819 \AA$.

In the following subsections, the adsorption energies, optimum binding distance between the molecular, charge transfer $(Q)$ between gas molecules and nanotube, electronic band structure, and total density of states of the (10,0) zigzag single-walled C-CNT, B-CNT, and Si-CNT that interacted with the considered gas molecule species are discussed. To establish a well-defined comparative study, we have performed the calculations using unit cells of similar sizes and parameters.

3.1. Interaction between Gas Molecule and Adsorbates. The adsorption of $\mathrm{H}_{2}, \mathrm{H}_{2} \mathrm{O}, \mathrm{O}_{2}, \mathrm{CO}, \mathrm{CO}_{2}, \mathrm{NO}, \mathrm{NO}_{2}, \mathrm{NH}_{3}$, and $\mathrm{CH}_{3} \mathrm{OH}$ on C-CNT, B-CNT, and Si-CNT are calculated and can be characterized as physisorption and chemisorption, as indicated by the magnitude of adsorption energy $\left(E_{\mathrm{ad}}\right)$ and binding distance (BD). Table 1 summarizes our results on the optimum stable binding tube-molecule distance (BD), adsorption energy $\left(E_{\mathrm{ad}}\right)$, and charge transfer $(Q)$ (positive $Q$ means charge transfer from molecule to tube) for a considered gas molecules adsorption on the proposed representative model of $(10,0)$ zigzag single-walled nanotube. In general, all these gas molecules are weakly bounded to the pristine carbon nanotube and the tube-molecule interaction can be identified as physisorption. Most molecules studied (with exception of $\mathrm{NO}_{2}$ and $\mathrm{O}_{2}$ ) are charge donors with small charge transfer ( 0.01 to 0.04 electron per molecule) and weak binding $(-0.2 \mathrm{eV})$. For $\mathrm{O}_{2}$ and $\mathrm{NO}_{2}$, both of which are charge acceptors, the charge transfer is not negligible. This is also reflected in their average adsorption energies. As it is known, pristine C-CNTs are rather inert and engage in only weak, van der Waals-type interactions with most molecules, due to their strong $\mathrm{sp}_{2}$ bonding network. The binding of $\mathrm{H}_{2}$ onto pristine CNT sidewalls are characterized as a physisorption interaction.

In contrast, our calculations show that the Boron doped carbon nanotube (B-CNT) exhibits significantly enhanced binding with $\mathrm{H}_{2}$, the concede adsorption energy $\left(E_{\mathrm{ad}}\right)$, and binding distance $(\mathrm{BD})$ between tube and molecules which are $-0.89 \mathrm{eV}$ and $1.83 \AA$. Our calculations indicate that $\mathrm{CO}, \mathrm{CO}_{2}$, and $\mathrm{NO}_{2}$ are also strongly chemisorbed on B-CNT and concede an adsorption energy $\left(E_{\mathrm{ad}}\right)$ values of $-2.33,-2.30$, and $-4.31 \mathrm{eV}$, respectively. In addition, $\mathrm{O}_{2}$ and $\mathrm{NO}$ due to strong exothermic process, can atom both completely dissociate into individual atoms that concede large adsorption energy values of -8.64 and $-7.24 \mathrm{eV}$ per molecule, respectively. On the other hand, the adsorption of $\mathrm{H}_{2} \mathrm{O}, \mathrm{CH}_{3} \mathrm{OH}$, and $\mathrm{NH}_{3}$ on B-CNT can be characterized as molecular chemisorption, as indicated by the average $E_{\mathrm{ad}}$ values. In particular, the binding strength of $\mathrm{H}_{2} \mathrm{O}, \mathrm{CH}_{3} \mathrm{OH}$, and $\mathrm{NH}_{3}$ is found to increase with respect to their tendency to donate electrons and concede adsorption energy values of $-1.19,-1.35$, and $-1.72 \mathrm{eV}$, respectively. The proposed model of silicon carbide nanotube (Si-CNT) also shows an improved chemisorbed adsorption energy as compared to pristine carbon nanotube but not with B-CNT. Our calculations indicate that $\mathrm{O}_{2}$ and $\mathrm{CH}_{3} \mathrm{OH}$ are strongly chemisorbed on $\mathrm{Si}-\mathrm{CNT}$ as compared to the CCNT and B-CNT. Si-CNT concede large adsorption energy values of -36.77 and $-3.42 \mathrm{eV}$ per molecule, respectively. On the other hand, the adsorption of $\mathrm{H}_{2}, \mathrm{H}_{2} \mathrm{O}, \mathrm{CO}, \mathrm{CO}_{2}, \mathrm{NO}$, $\mathrm{NO}_{2}$, and $\mathrm{NH}_{3}$ on Si-CNT concede lower adsorption energy values of $-0.32,-0.45,-0.74,-0.63,-0.23,-1.45$, and -0.24 per molecule, respectively, as compared to B-CNT. But while comparing with $\mathrm{C}-\mathrm{CNT}$, Si-CNT shows a higher adsorption energy with respect to all the gas molecules considered. In Table 1, we show the large adsorption energy values for each gas molecules in a bold face letter. The comparative DFT study result shows that the $\mathrm{B}-\mathrm{CNT}$ and $\mathrm{Si}-\mathrm{CNT}$ adsorbent materials which show a strong accept or donor of electron with respect to specific gas molecules, and it could be favor adsorbates for various specific gas sensor applications. 


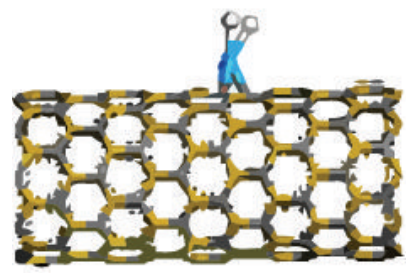

(a)

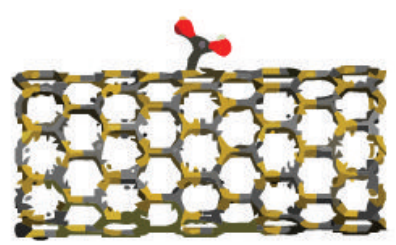

(e)

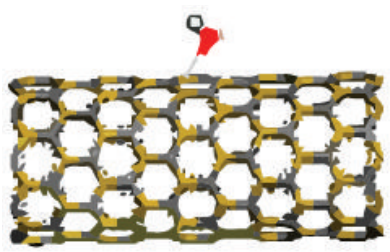

(b)

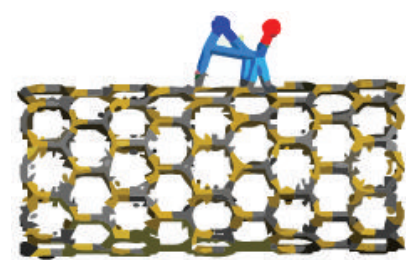

(f)

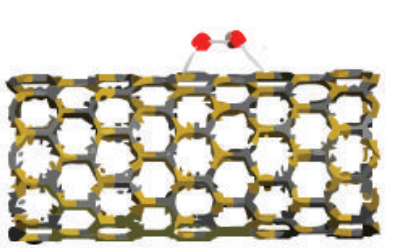

(c)

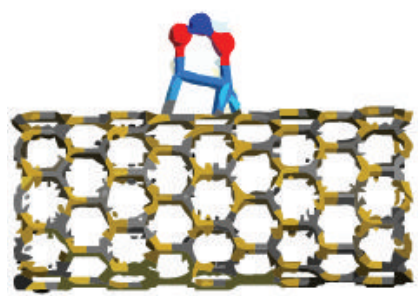

(g)

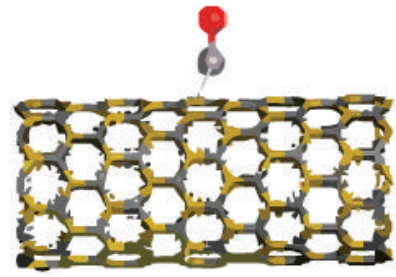

(d)

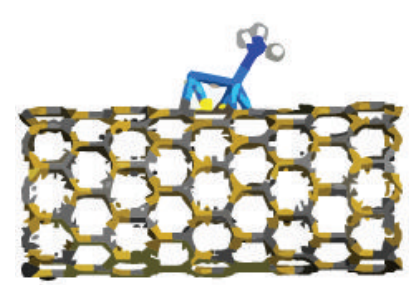

(h)

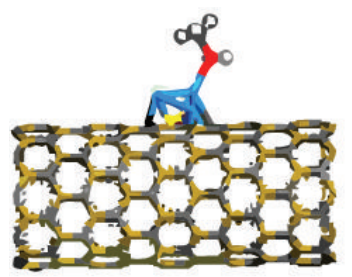

(i)

Figure 2: Optimized stable configurations of the Si-CNT nanotube adsorbates with considered gas molecules: (a) $\mathrm{H}_{2}$, (b) $\mathrm{H}_{2} \mathrm{O}$, (c) $\mathrm{O}_{2}$, (d) $\mathrm{CO}$, (e) $\mathrm{CO}_{2}$, (f) $\mathrm{NO}$, (g) $\mathrm{NO}_{2}$, (h) $\mathrm{NH}_{3}$, (i) $\mathrm{CH}_{3} \mathrm{OH}$.

TABLE 1: Adsorption energy $\left(E_{\mathrm{ad}}\right)$ per molecule, binding distance $(\mathrm{BD})$ and charge transfer $(Q)$ (positive $Q$ means charge transfer from molecule to tube) for a considered gas molecules on the specified adsorbent model.

\begin{tabular}{lccccccccccc}
\hline Adsorbents model & & $\mathrm{H}_{2}$ & $\mathrm{H}_{2} \mathrm{O}$ & $\mathrm{O}_{2}$ & $\mathrm{CO}$ & $\mathrm{CO}_{2}$ & $\mathrm{NO}^{2}$ & $\mathrm{NO}_{2}$ & $\mathrm{NH}_{3}$ & $\mathrm{CH}_{3} \mathrm{OH}^{2}$ \\
\hline (10, 0) Pristine carbon & $E_{\text {ad }}(\mathrm{eV})$ & -0.12 & & -0.51 & & -0.97 & -0.041 & -0.78 & -0.15 & -3.35 \\
nanotube (C-CNT) & $\mathrm{BD}(\AA)$ & 2.81 & No binding & 2.32 & No binding & 3.20 & 3.46 & 1.93 & 2.99 & 1.96 \\
& $\mathrm{Q}(\mathrm{e})$ & 0.014 & & -0.13 & & 0.018 & 0.009 & -0.064 & 0.033 & 0.013 \\
\hline (10,0) Boron doped & $E_{\text {ad }}(\mathrm{eV})$ & $-\mathbf{0 . 8 9}$ & $-\mathbf{1 . 1 9}$ & -8.64 & $-\mathbf{2 . 3 3}$ & $-\mathbf{2 . 2 0}$ & $-\mathbf{- 7 . 2 4}$ & $-\mathbf{4 . 3 1}$ & $-\mathbf{1 . 7 2}$ & -1.35 \\
carbon nanotube & $\mathrm{BD}(\AA)$ & 1.83 & 2.24 & 1.76 & 2.03 & 2.02 & 1.75 & 1.96 & 2.26 & 2.19 \\
$(\mathrm{~B}-\mathrm{CNT})$ & $\mathrm{Q}(\mathrm{e})$ & 0.12 & 0.16 & 0.21 & 0.19 & 0.18 & 0.20 & 0.21 & 0.16 & 0.13 \\
\hline \multirow{2}{*}{ (10,0) Silicon carbide } & $E_{\text {ad }}(\mathrm{eV})$ & -0.32 & -0.45 & $-\mathbf{3 6 . 7 7}$ & -0.74 & -0.63 & -0.23 & -1.45 & -0.24 & $-\mathbf{3 . 4 2}$ \\
nanotube (Si-CNT) & $\mathrm{BD}(\AA)$ & 2.05 & 2.62 & 1.72 & 1.93 & 1.82 & 2.51 & 2.01 & 2.87 & 1.98 \\
& $\mathrm{Q}(\mathrm{e})$ & 0.10 & 0.11 & 0.23 & 0.17 & 0.12 & 0.08 & 0.18 & 0.09 & 0.20 \\
\hline
\end{tabular}

3.2. Electronic Properties of Gas Adsorbates upon Molecule Adsorption. To further understand the adsorption properties of considered gas molecules on the proposed representative model and the gas adsorbed nanotube electronic structure are calculated in terms of electronics band structure and density of state (DOS) for the B-CNT and Si-CNT system. In this paper, our choice of interested models are B-CNT and $\mathrm{Si}-\mathrm{CNT}$. In this section, we discuss the electronic band structure and density of state of adsorbates B-CNT and SiCNT upon each gas molecule adsorption condition. Before that, we calculated the electronic band structure and density of state of the proposed B-CNT and Si-CNT adsorbate model without gas molecule adsorption condition. The electronic band structure and density of state of adsorbate nanotubes are shown in Figures 3, 6(a), 6(b), and 6(c), respectively. There Fermi energy $\left(E_{F}\right)$ levels are denoted by dashed line and their respective values are $E_{F}=1.3 \mathrm{ev}$ and $E_{F}=-4.36$.

Figures 4 and 5 show the electronic band strucutre for the considered gas molecule adsorbed on the B-CNT and SiCNT systems. Figures 7 and 8 show the electronic density of states (DOS) for the considered gas molecule adsorped on the B-CNT and Si-CNT systems. It can be seen that the DOS near the Fermi level $\left(E_{F}\right)$ is affected by the adsorption of considered gas molecule in the B-CNT and Si-CNT surface. 


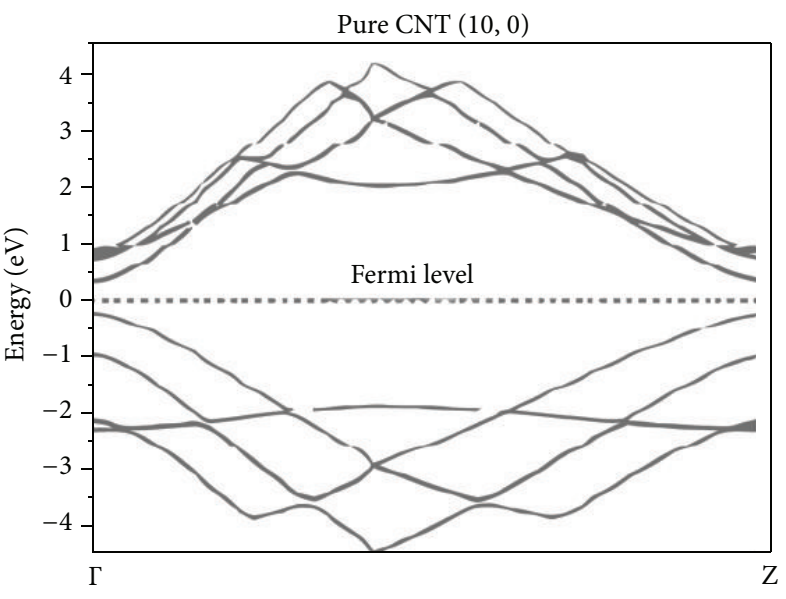

(a)

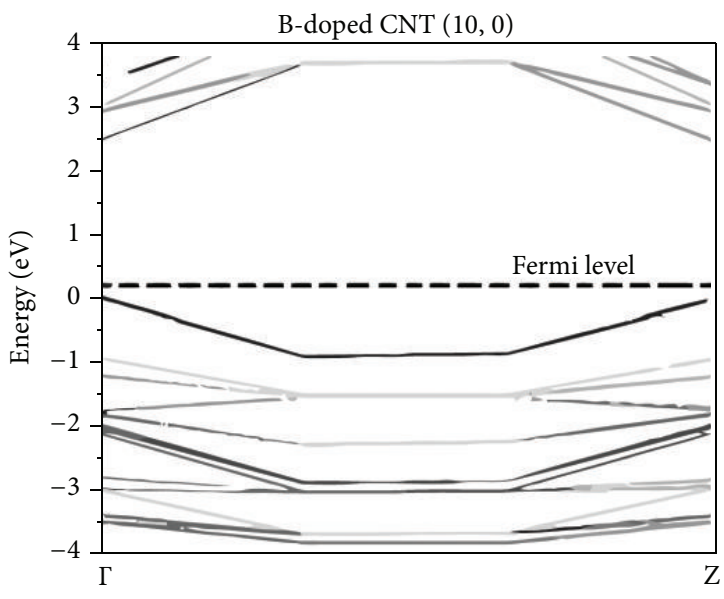

(b)

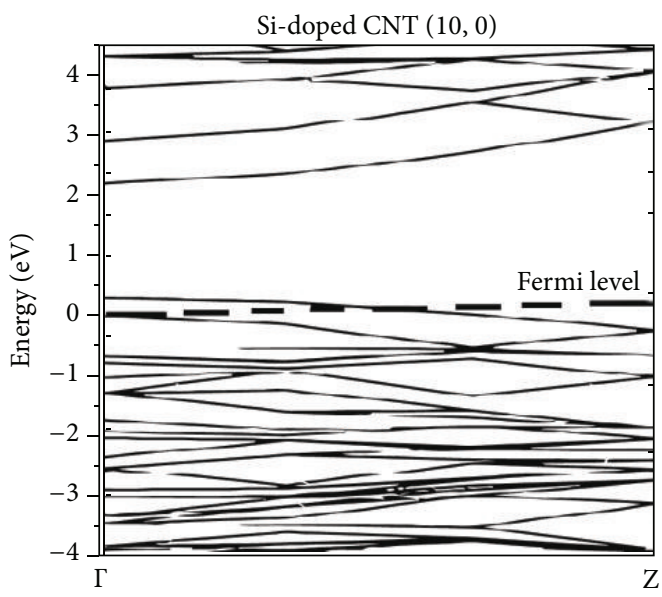

(c)

FIGURE 3: Band structures of the (10, 0) indexed: (a) pure carbon nanotube, (b) boron doped carbon nanotube (B-CNT), and (c) silicon doped carbon nanotube (Si-CNT) without gas molecules adsorption condition. The dashed lines indicate the position of Fermi level.

TABLE 2: Fermi energy $\left(E_{F}\right)$ of the B-CNT and Si-CNT models with and without adsorption of considered gas molecules.

\begin{tabular}{|c|c|c|c|c|c|c|c|c|c|}
\hline \multirow{2}{*}{ Adsorbents model } & \multicolumn{9}{|c|}{ Fermi energy $E_{F}(\mathrm{eV})$} \\
\hline & $\mathrm{H}_{2}$ & $\mathrm{H}_{2} \mathrm{O}$ & $\mathrm{O}_{2}$ & $\mathrm{CO}$ & $\mathrm{CO}_{2}$ & $\mathrm{NO}$ & $\mathrm{NO}_{2}$ & $\mathrm{NH}_{3}$ & $\mathrm{CH}_{3} \mathrm{OH}$ \\
\hline \multicolumn{10}{|c|}{$(10,0)$ Boron doped carbon nanotube (B-CNT) } \\
\hline Without gas molecule adsorption & \multicolumn{9}{|c|}{1.3} \\
\hline With gas molecule adsorption & -7.3 & -5.9 & -8.5 & -8.2 & -9.7 & -7.5 & -8.4 & -8.6 & -8.2 \\
\hline \multicolumn{10}{|l|}{$\begin{array}{l}(10,0) \text { Silicon carbide nanotube (Si-CNT) } \\
\end{array}$} \\
\hline Without gas molecule adsorption & \multicolumn{9}{|c|}{-4.36} \\
\hline With gas molecule adsorption & -2.5 & -3.5 & -3.6 & -3.1 & -3.2 & -3.5 & -3.2 & -4.1 & -2.2 \\
\hline
\end{tabular}

The Fermi energy $\left(E_{F}\right)$ values of the gas adsorped adsorbent nanotube are summarized in Table 2 . From the comparison, we can also see that the DOS of the B-CNT and Si-CNT where the gas molecule is adsorbed shifts down or upward by some amount of $\mathrm{eV}$ in comparison with a bare $(10,0)$ B-CNT and Si-CNT. This substantial shift can be explained by the reduction in effective Coulomb potential due to the charge transfer. On the other hand, the difference in the
Fermi level of the B-CNT and Si-CNT clearly shows a charge transfer between the considered gas molecule and B$\mathrm{CNT}$ and Si-CNT system in the adsorption process. From the DFT comparative study, we recommend (based on the adsorption energy between the considered gas molecules and adsorbents nanotube model) a high sensitive specified adsorbates nanotube model for the considered gas molecules shown in Table 3. 


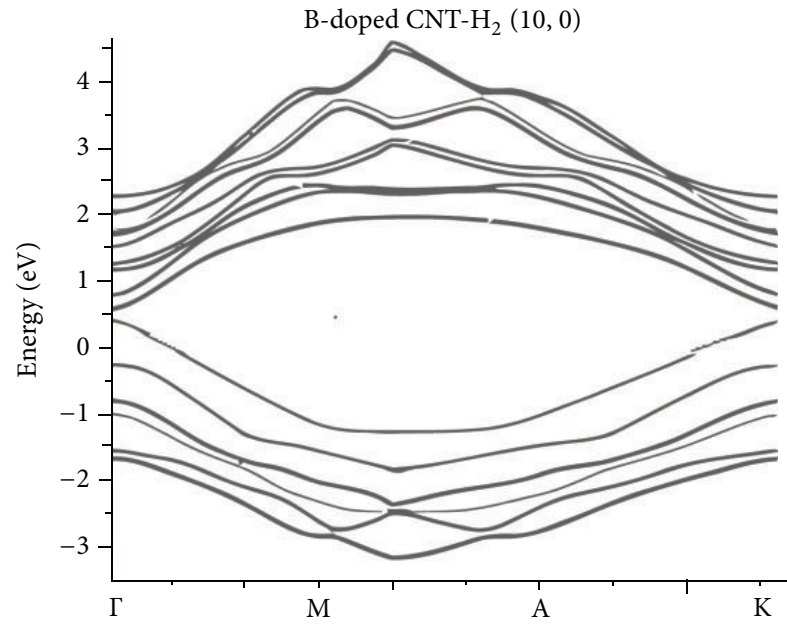

(a)

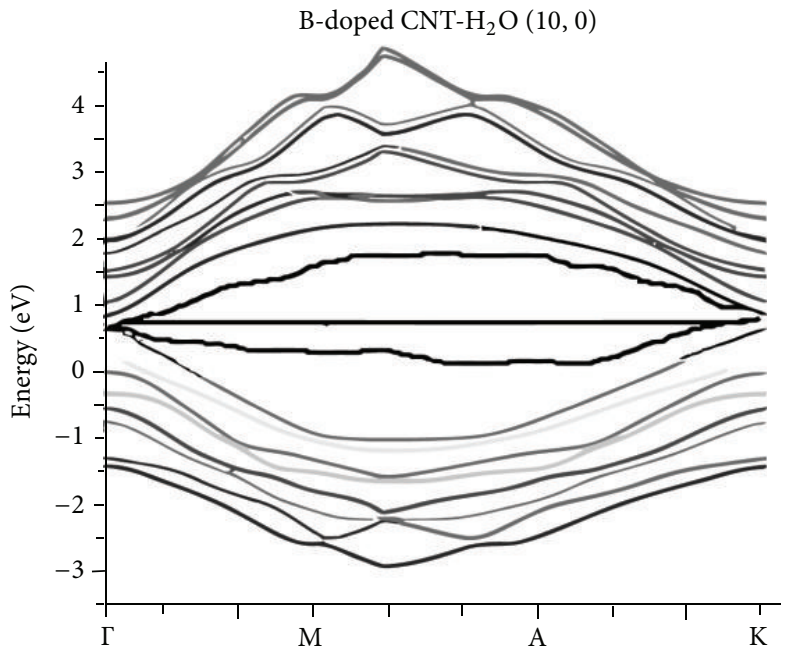

(c)

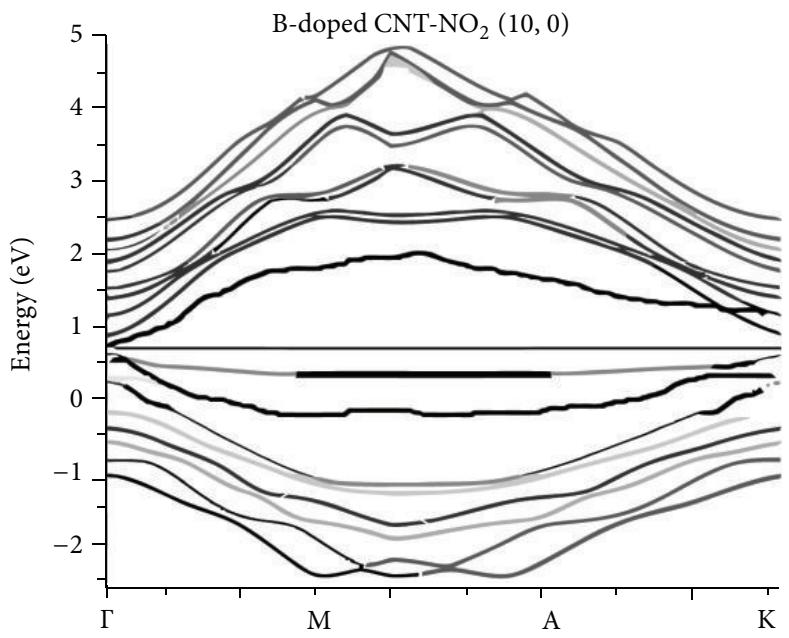

(e)

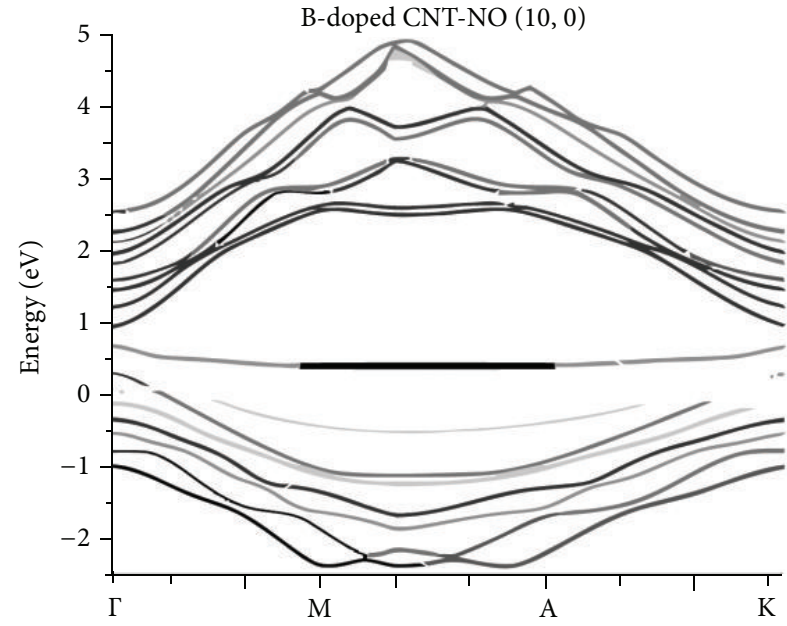

(b)

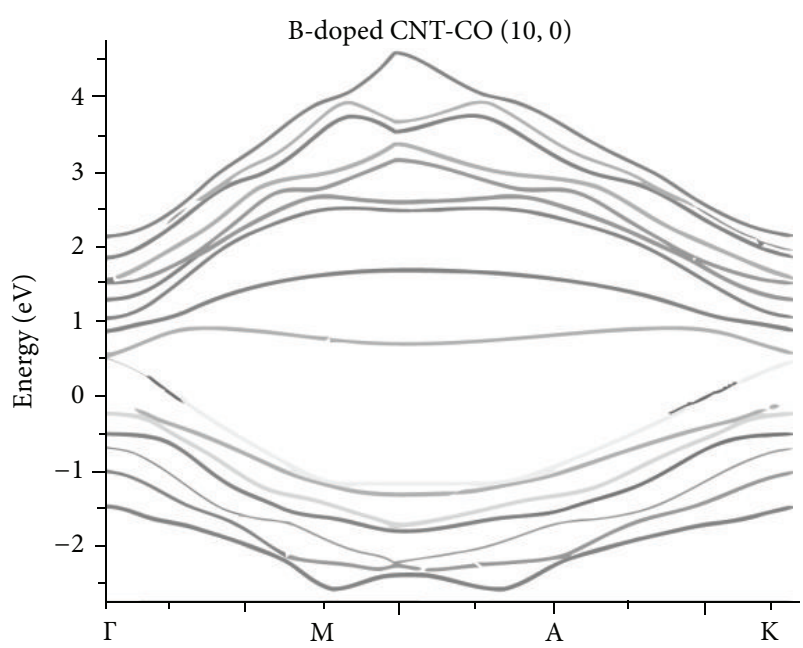

(d)

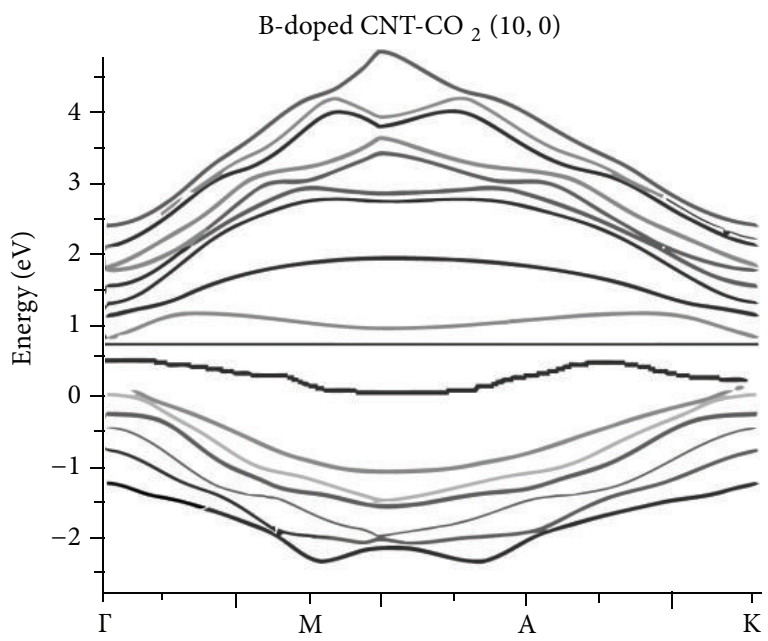

(f)

FIGURE 4: Electronic band structures for the $(10,0)$ boron doped CNT (B-CNT) adsorbates with considered gas molecules adsorption condition: (a) $\mathrm{H}_{2}$, (b) $\mathrm{NO}$, (c) $\mathrm{H}_{2} \mathrm{O}$, (d) $\mathrm{CO}$, (e) $\mathrm{NO}_{2}$, (f) $\mathrm{CO}_{2}$. 


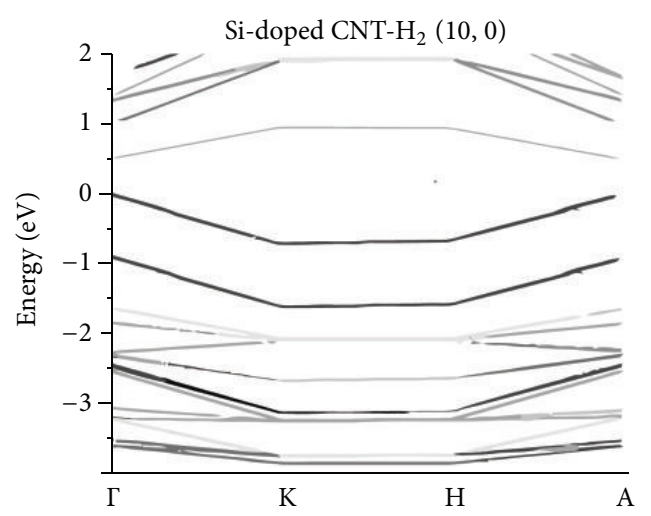

(a)

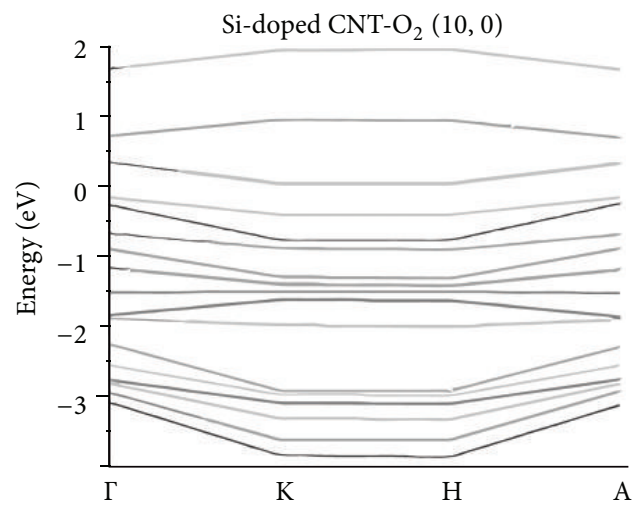

(c)

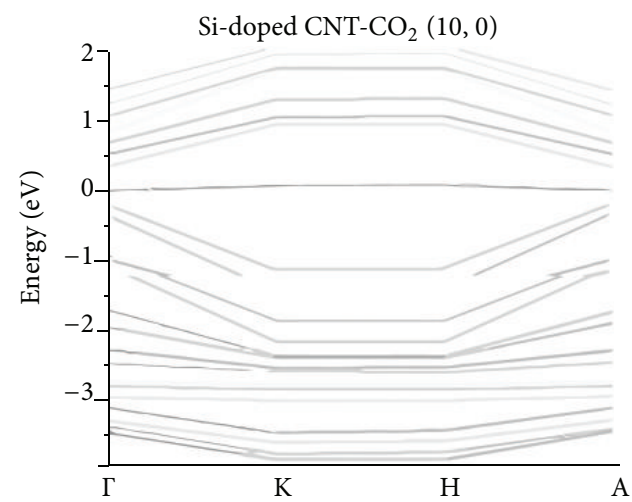

(e)

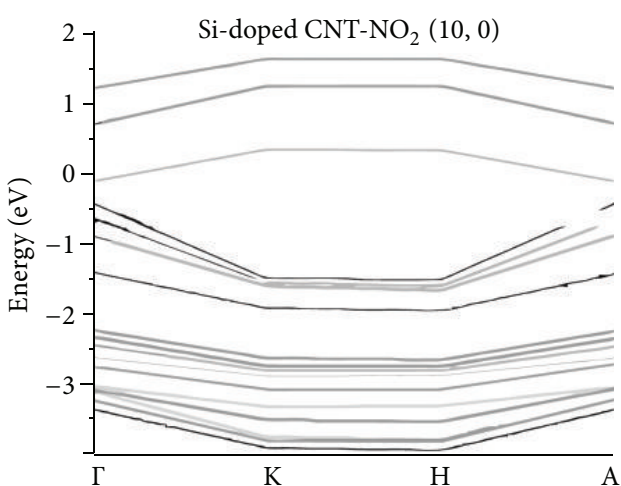

(g)

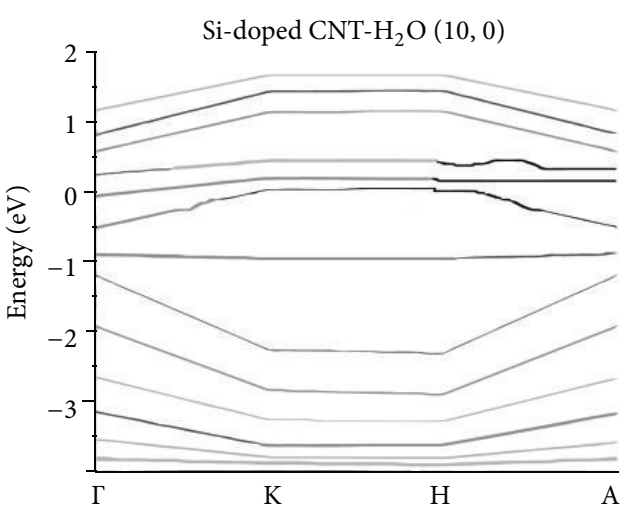

(b)

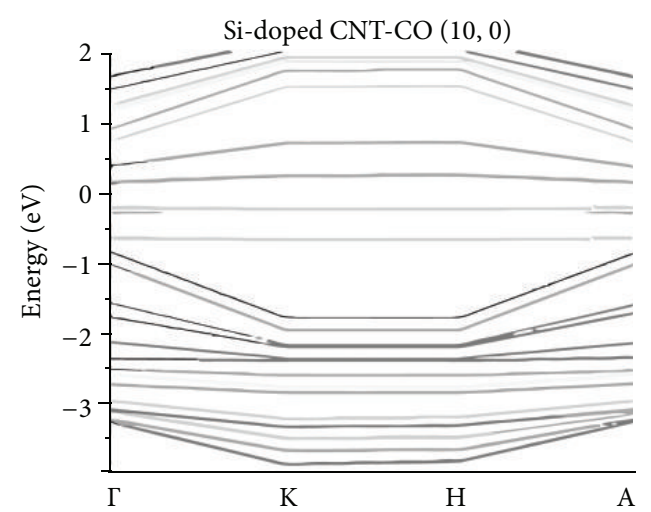

(d)

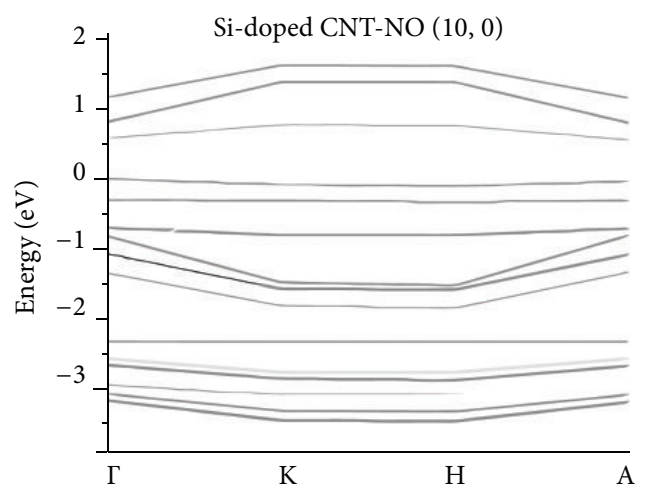

(f)

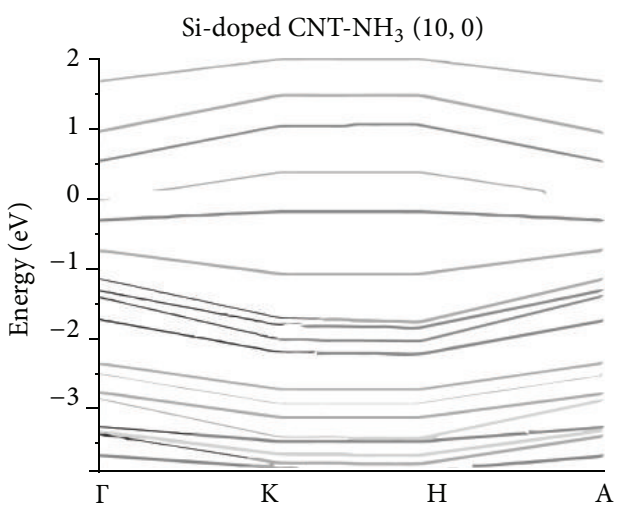

(h)

FIgure 5: Continued. 


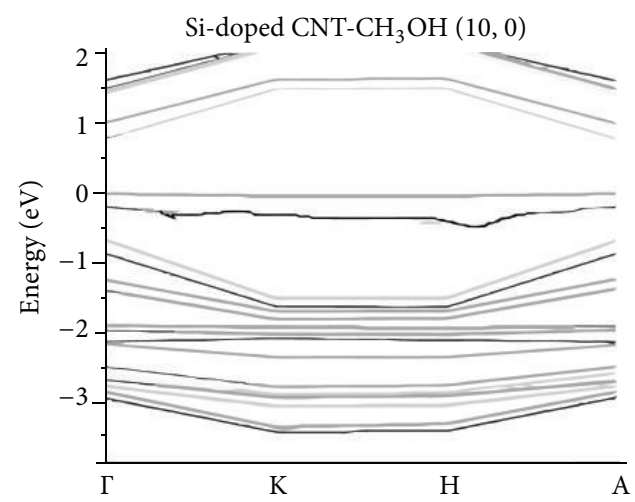

(i)

FIGURE 5: Electronic band structures for the $(10,0)$ silicon doped CNT (Si-CNT) adsorbates with considered gas molecules adsorption condition: (a) $\mathrm{H}_{2}$, (b) $\mathrm{H}_{2} \mathrm{O}$, (c) $\mathrm{O}_{2}$, (d) $\mathrm{CO}$, (e) $\mathrm{CO}_{2}$, (f) $\mathrm{NO}$, (g) $\mathrm{NO}_{2}$, (h) $\mathrm{NH}_{3}$, (i) $\mathrm{CH}_{3} \mathrm{OH}$.

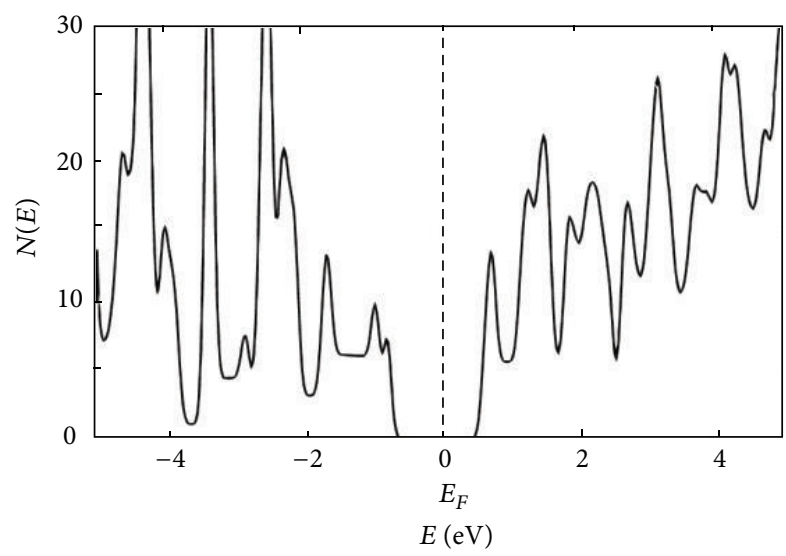

(a)

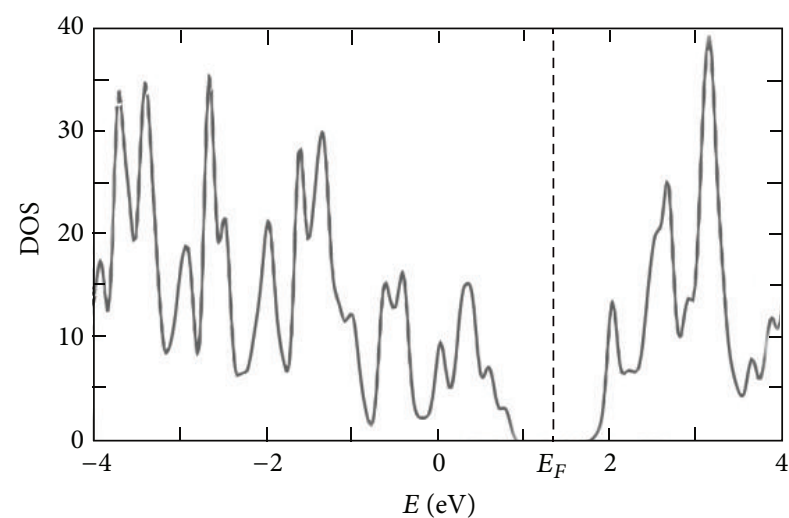

(b)

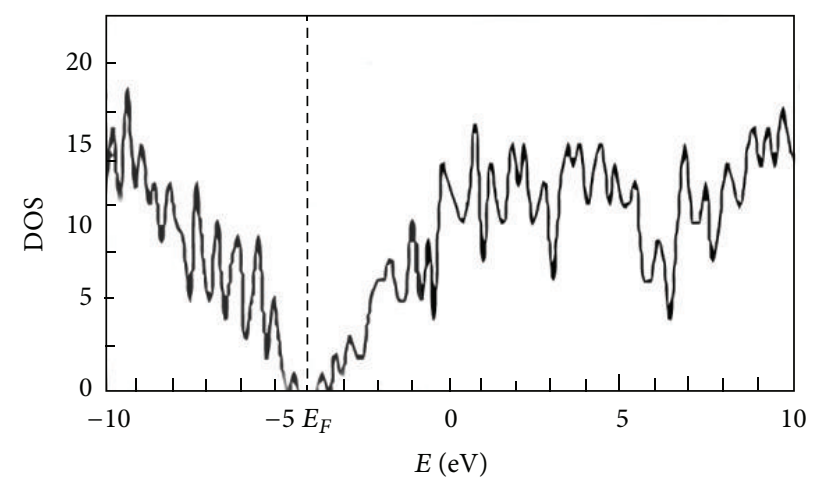

(c)

Figure 6: Electronic density of states of the adsorbents without gas molecule adsorption condition: (a) (10, 0) zigzag single-walled C-CNT, (b) $(10,0)$ zigzag single-walled B-CNT, and (c) $(10,0)$ zigzag single-walled Si-CNT.

\section{Conclusion}

We perform first-principle DFT studies on the adsorption of nine predominate gas molecules $\left(\mathrm{H}_{2}, \mathrm{H}_{2} \mathrm{O}, \mathrm{O}_{2}, \mathrm{CO}, \mathrm{CO}_{2}, \mathrm{NO}\right.$, $\mathrm{NO}_{2}, \mathrm{NH}_{3}$, and $\mathrm{CH}_{3} \mathrm{OH}$ ) on a C-CNT, B-CNT, and Si-CNT $(10,0)$ zigzag single-walled adsorbent nanotube material. We found that all molecules are weakly adsorbed on pristine carbon nanotube adsorbent with small binding energy, while they can be either charge donor or accepter of nanotube. Finally, we found that the B-CNT and Si-CNT adsorbents are highly chemisorption when exposed to $\mathrm{NO}, \mathrm{NO}_{2}$, and $\mathrm{O}_{2}, \mathrm{CH}_{3} \mathrm{OH}$. The Si-CNT adsorbent also moderately adsorbs $\mathrm{H}_{2}, \mathrm{H}_{2} \mathrm{O}, \mathrm{CO}, \mathrm{CO}_{2}$, and $\mathrm{NH}_{3}$ gas molecules with binding strengths compared with $\mathrm{B}-\mathrm{CNT}$ adsorbates. The electronic 


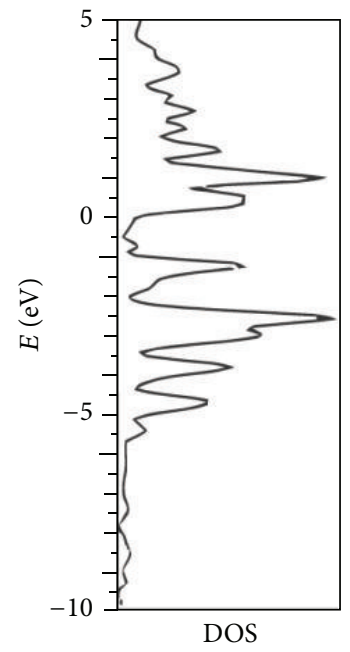

(a)

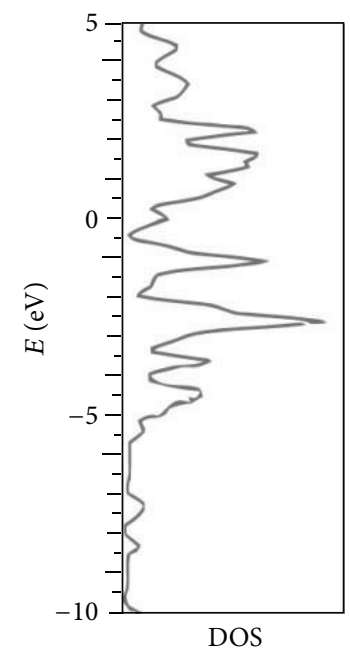

(e)

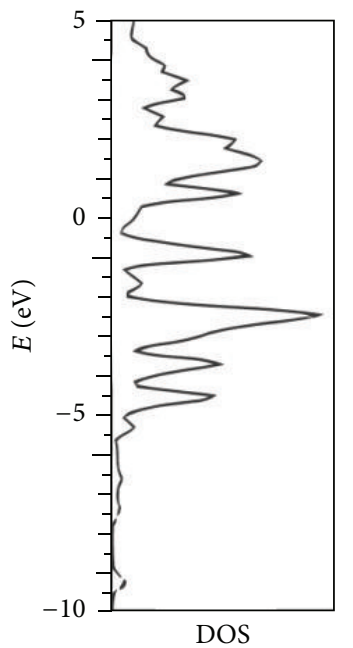

(b)

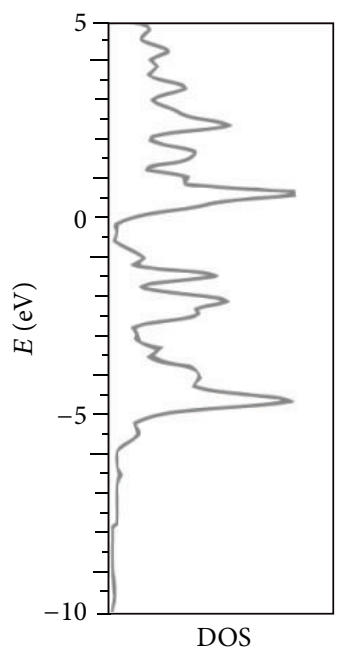

(f)

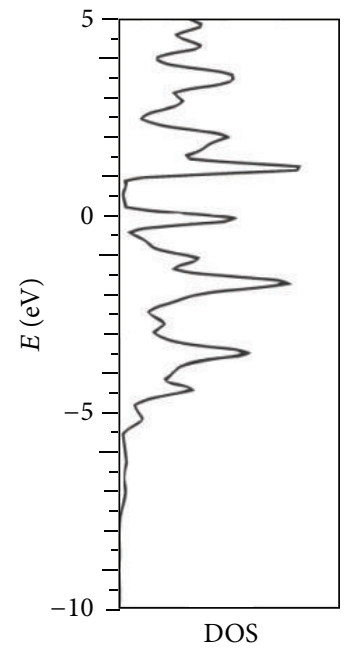

(c)

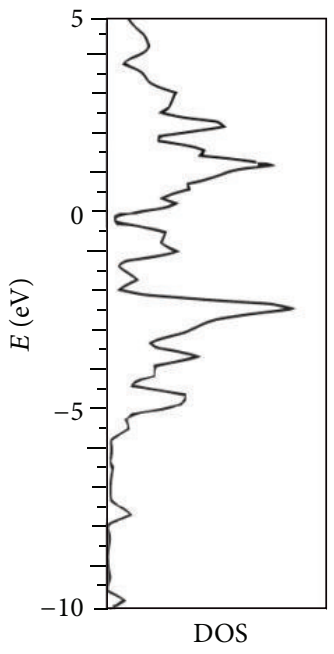

(g)

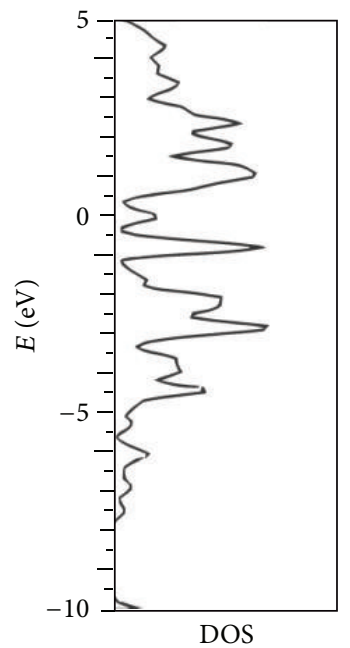

(d)

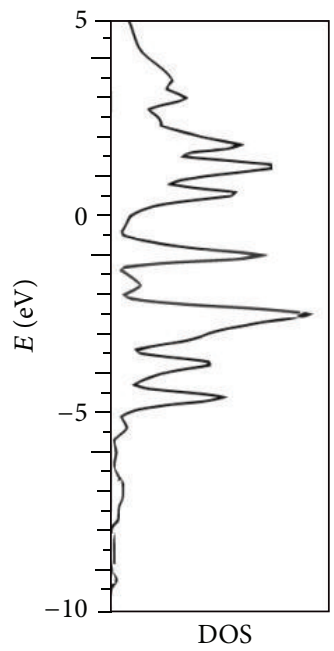

(h)

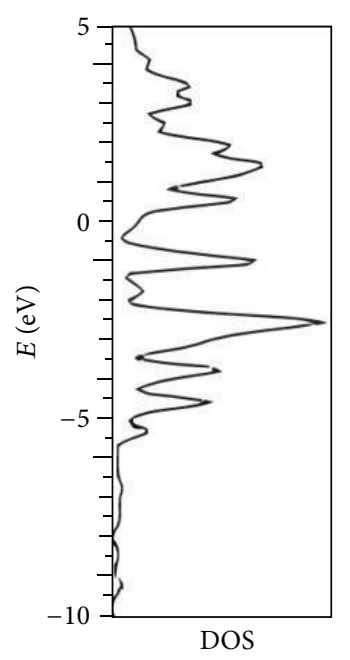

(i)

FIGURE 7: Electronic density of states (DOS) of the B-CNT adsorbates with considered gas molecules adsorption condition: (a) $\mathrm{H}_{2}$, (b) $\mathrm{H}_{2} \mathrm{O}$, (c) $\mathrm{O}_{2}$, (d) $\mathrm{CO}$, (e) $\mathrm{CO}_{2}$, (f) $\mathrm{NO}$, (g) $\mathrm{NO}_{2}$, (h) $\mathrm{NH}_{3}$, (i) $\mathrm{CH}_{3} \mathrm{OH}$ 


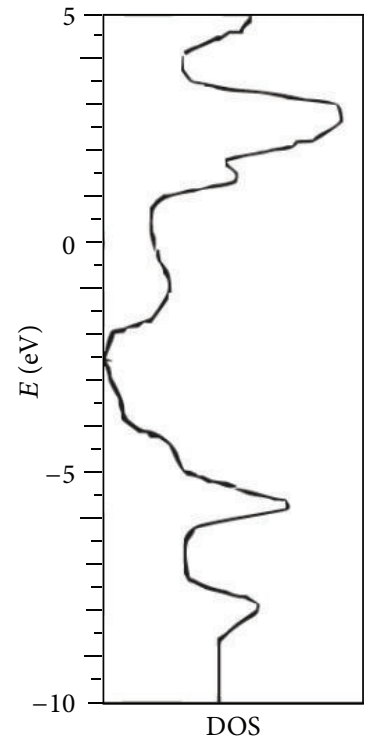

(a)

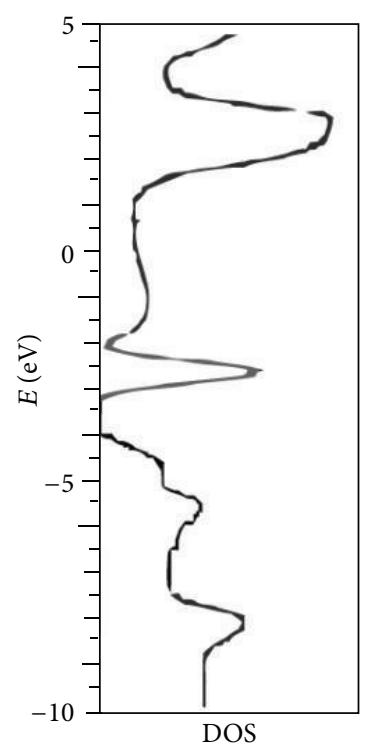

(e)

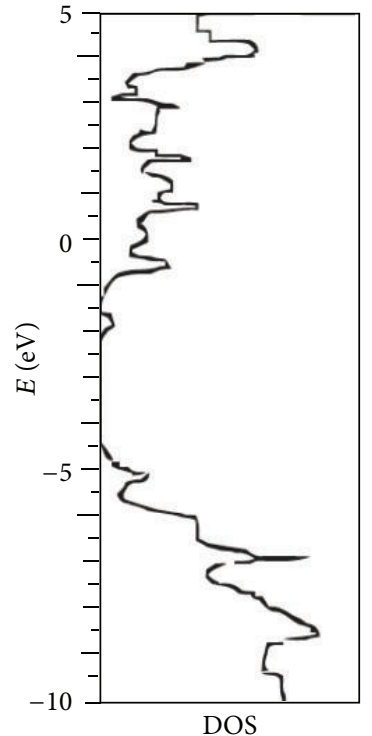

(b)

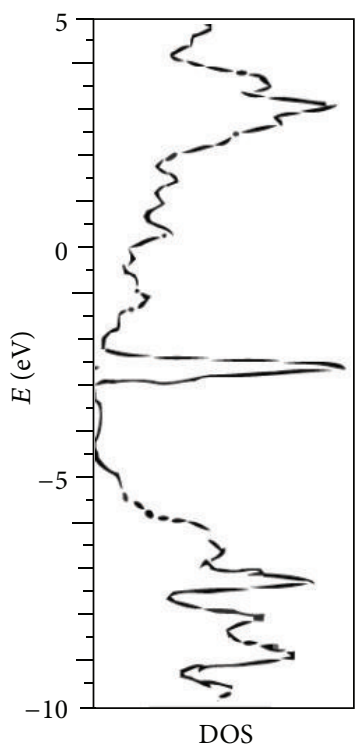

(f)

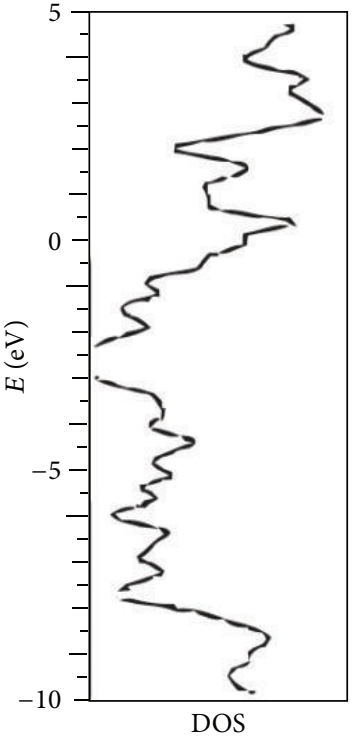

(c)

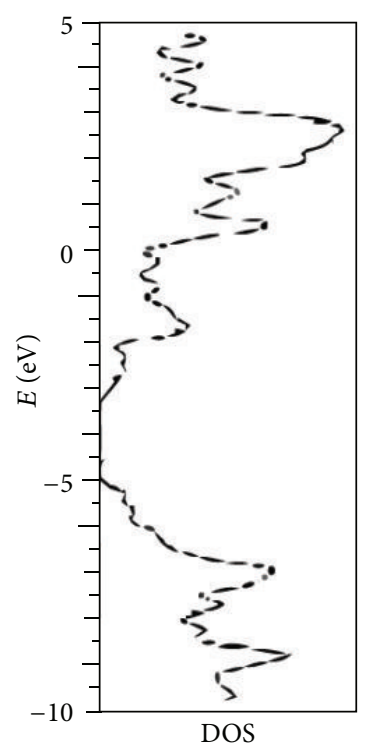

(g)

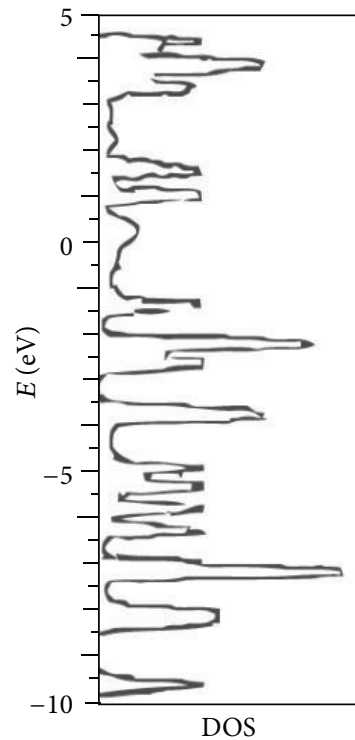

(d)

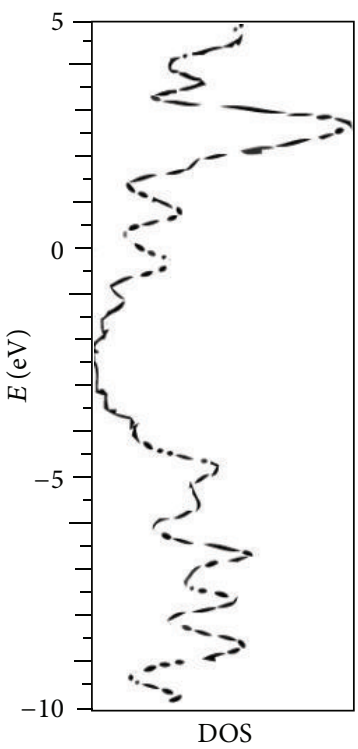

(h)

FIGURE 8: Electronic density of states (DOS) of the $\mathrm{Si}-\mathrm{CNT}$ adsorbates with considered gas molecules adsorption condition: (a) $\mathrm{H}_{2}$, (b) $\mathrm{H}_{2} \mathrm{O}$, (c) $\mathrm{O}_{2}$, (d) $\mathrm{CO},(\mathrm{e}) \mathrm{NO}$, (f) $\mathrm{NO}_{2}$, (g) $\mathrm{NH}_{3}$, (h) $\mathrm{CH}_{3} \mathrm{OH}$.

TABLE 3: Recommendations for a high sensitive specified adsorbate model for considered gas molecules.

\begin{tabular}{lcc}
\hline Gas molecules & Adsorption type & High sensitive adsorbate model \\
\hline $\mathrm{H}_{2}, \mathrm{H}_{2} \mathrm{O}, \mathrm{NO}, \mathrm{NO}_{2}, \mathrm{CO}, \mathrm{CO}_{2}$, and $\mathrm{NH}_{3}$ & Chemisorption & Boron doped carbon (B-CNT) nanotubes \\
$\mathrm{O}_{2}$ and $\mathrm{CH}_{2} \mathrm{OH}$ & Chemisorption & Silicon doped carbon (Si-CNT) nanotubes \\
\hline
\end{tabular}

band structure and DOS calculations of these systems show that the strong adsorption (chemisorption) of considered gas molecules is able to show dramatic changes in the density of states near the Fermi level. The quantum molecular dynamic (MD) simulation carried out at room temperature and results show that the B-CNT and Si-CNT adsorbent materials would be good candidates for gas sensor applications. Finally, the proposed methodology of designing gas sensors can be followed to fabricate reliable, sensitive, and selective nanotube sensors. 


\section{References}

[1] M. S. Dresselhaus, G. Dressehaus, and P. C. Eklund, Science of Fullerenes and Carbon Nanotubes, Academic Press, New York, NY, USA, 1996.

[2] T. Ebbesen, Carbon Nanotube: Preparation and Properties, CRC Press, Boca Raton, Fla, USA, 1997.

[3] R. Saito, G. Dressehaus, and M. S. Dresselhaus, Physics Properties of Carbon Nanotubes, World Scientific, New York, NY, USA, 1998.

[4] J. P. Lu and J. Han, "Carbon nanotubes and nanotube-based nano devices," Journal of High Electronics and System, vol. 9, p. 101, 1998.

[5] J. Zhao, A. Buldum, J. Han, and J. P. Lu, "Gas molecule adsorption in carbon nanotubes and nanotube bundles," Nanotechnology, vol. 13, no. 2, pp. 195-200, 2002.

[6] S. Santucci, S. Picozzi, F. Di Gregorio et al., " $\mathrm{NO}_{2}$ and $\mathrm{CO}$ gas adsorption on carbon nanotubes: experiment and theory," Journal of Chemical Physics, vol. 119, no. 20, pp. 10904-10910, 2003.

[7] A. Ricca and C. W. Bauschlicher Jr., "The adsorption of $\mathrm{NO}_{2}$ on $(9,0)$ and $(10,0)$ carbon nanotubes," Chemical Physics, vol. 323, no. 2-3, pp. 511-518, 2006.

[8] A. Ricca and C. W. Bauschlicher Jr., "The physisorption of $\mathrm{CH}_{4}$ on graphite and on a $(9,0)$ carbon nanotube," Chemical Physics, vol. 324, no. 2-3, pp. 455-458, 2006.

[9] A. A. Rafati, S. M. Hashemianzadeh, and Z. B. Nojini, "Electronic properties of adsorption nitrogen monoxide on inside and outside of the armchair single wall carbon nanotubes: a density functional theory calculations," Journal of Physical Chemistry C, vol. 112, no. 10, pp. 3597-3604, 2008.

[10] P. A. Denis, "Methane adsorption inside and outside pristine and N-doped single wall carbon nanotubes," Chemical Physics, vol. 353, no. 1-3, pp. 79-86, 2008.

[11] T. Zhang, S. Mubeen, N. V. Myung, and M. A. Deshusses, "Recent progress in carbon nanotube-based gas sensors," Nanotechnology, vol. 19, no. 33, Article ID 332001, 2008.

[12] Z. Zanolli and J.-C. Charlier, "Defective carbon nanotubes for single-molecule sensing," Physical Review B, vol. 80, no. 15, Article ID 155447, 2009.

[13] S. Tang and Z. Cao, "Defect-induced chemisorption of nitrogen oxides on $(10,0)$ single-walled carbon nanotubes: insights from density functional calculations," Journal of Chemical Physics, vol. 131, no. 11, Article ID 114706, 2009.

[14] G. P. Lithoxoos, A. Labropoulos, L. D. Peristeras, N. Kanellopoulos, J. Samios, and I. G. Economou, "Adsorption of $\mathrm{N}_{2}$, $\mathrm{CH}_{4}, \mathrm{CO}$ and $\mathrm{CO}_{2}$ gases in single walled carbon nanotubes: a combined experimental and Monte Carlo molecular simulation study," Journal of Supercritical Fluids, vol. 55, no. 2, pp. 510-523, 2010.

[15] K. Azizi, S. M. Hashemianzadeh, and S. Bahramifar, "Density functional theory study of carbon monoxide adsorption on the inside and outside of the armchair single-walled carbon nanotubes," Current Applied Physics, vol. 11, no. 3, pp. 776-782, 2011.

[16] J. Zhang, K. P. Loh, J. Zheng, M. B. Sullivan, and P. Wu, “Adsorption of molecular oxygen on the walls of pristine and carbondoped $(5,5)$ boron nitride nanotubes: spin-polarized density functional study," Physical Review B, vol. 75, no. 24, Article ID 245301, 2007.

[17] R. J. Baierle, T. M. Schmidt, and A. Fazzio, "Adsorption of CO and NO molecules on carbon doped boron nitride nanotubes," Solid State Communications, vol. 142, no. 1-2, pp. 49-53, 2007.
[18] J.-X. Zhao and Y.-H. Ding, “Theoretical studies of the interaction of an open-ended boron nitride nanotube (BNNT) with gas molecules," Journal of Physical Chemistry C, vol. 112, no. 51, pp. 20206-20211, 2008.

[19] R. Wang and D. Zhang, "Theoretical study of the adsorption of carbon monoxide on pristine and silicon-doped boron nitride nanotubes," Australian Journal of Chemistry, vol. 61, no. 12, pp. 941-945, 2008.

[20] Q. Dong, X. M. Li, W. Q. Tian, X.-R. Huang, and C.-C. Sun, "Theoretical studies on the adsorption of small molecules on Ptdoped BN nanotubes," Journal of Molecular Structure, vol. 948, no. 1-3, pp. 83-92, 2010.

[21] R. Geetha and V. Gayathri, "Comparative study on gas adsorption in defected carbon and boron nitride nanotube," Current Nanoscience, vol. 6, no. 2, pp. 131-136, 2010.

[22] M. T. Baei, A. R. Soltani, A. V. Moradi, and E. Tazikeh Lemeski, "Adsorption properties of $\mathrm{N}_{2} \mathrm{O}$ on $(6,0),(7,0)$, and $(8,0)$ zigzag single-walled boron nitride nanotubes: a computational study," Computational and Theoretical Chemistry, vol. 970, no. 1-3, pp. 30-35, 2011.

[23] Z. Zhou, J. Zhao, Z. Chen et al., "Comparative study of hydrogen adsorption on carbon and BN nanotubes," Journal of Physical Chemistry B, vol. 110, no. 27, pp. 13363-13369, 2006.

[24] L. Bai and Z. Zhou, "Computational study of B- or N-doped single-walled carbon nanotubes as $\mathrm{NH}_{3}$ and $\mathrm{NO}_{2}$ sensors," Carbon, vol. 45, no. 10, pp. 2105-2110, 2007.

[25] W. An and C. H. Turner, "Electronic structure calculations of gas adsorption on boron-doped carbon nanotubes sensitized with tungsten," Chemical Physics Letters, vol. 482, no. 4-6, pp. 274-280, 2009.

[26] J. A. Talla, "First principles modeling of boron-doped carbon nanotube sensors," Physica B, vol. 407, no. 6, pp. 966-970, 2012.

[27] J. Debnarayan, S. Chia-Liang, C. Li-Chyong, and C. KueiHsien, "Effect of chemical doping of boron and nitrogen on the electronic, optical, and electrochemical properties of carbon nanotubes," Progress in Materials Science, vol. 58, pp. 565-635, 2013.

[28] C. Pham-Huu, N. Keller, G. Ehret, and M. J. Ledoux, “The first preparation of silicon carbide nanotubes by shape memory synthesis and their catalytic potential," Journal of Catalysis, vol. 200, no. 2, pp. 400-410, 2001.

[29] X.-H. Sun, C.-P. Li, W.-K. Wong et al., "Formation of silicon carbide nanotubes and nanowires via reaction of silicon (from disproportionation of silicon monoxide) with carbon nanotubes," Journal of the American Chemical Society, vol. 124, no. 48, pp. 14464-14471, 2002.

[30] R. Q. Wu, M. Yang, Y. H. Lu, Y. P. Feng, Z. G. Huang, and Q. Y. $\mathrm{Wu}$, "Silicon carbide nanotubes as potential gas sensors for $\mathrm{CO}$ and HCN detection," Journal of Physical Chemistry C, vol. 112, no. 41, pp. 15985-15988, 2008.

[31] W. An, X. Wu, and X. C. Zeng, "Adsorption of $\mathrm{O}_{2}, \mathrm{H}_{2}, \mathrm{CO}, \mathrm{NH}_{3}$, and $\mathrm{NO}_{2}$ on $\mathrm{ZnO}$ nanotube: a density functional theory study," Journal of Physical Chemistry C, vol. 112, no. 15, pp. 5747-5755, 2008.

[32] G. Gao and H. S. Kang, "First principles study of NO and NNO chemisorption on silicon carbide nanotubes and other nanotubes," Journal of Chemical Theory and Computation, vol. 4, no. 10, pp. 1690-1697, 2008.

[33] M. D. Ganji, "Theoretical study of the adsorption of $\mathrm{CO}_{2}$ on tungsten carbide nanotubes," Physics Letters A, vol. 372, no. 18, pp. 3277-3282, 2008. 
[34] R. Ding, Y. Yang, and L. Liu, "Working mechanism of a SiC nanotube $\mathrm{NO}_{2}$ gas sensor," Journal of Semiconductors, vol. 30, no. 11, Article ID 114010, 4 pages, 2009.

[35] G. Gao, S. H. Park, and H. S. Kang, "A first principles study of $\mathrm{NO}_{2}$ chemisorption on silicon carbide nanotubes," Chemical Physics, vol. 355, no. 1, pp. 50-54, 2009.

[36] F. Lin, G. Zhou, Z. Li, J. Li, J. Wu, and W. Duan, "Molecular and atomic adsorption of hydrogen on $\mathrm{TiO}_{2}$ nanotubes: an $\mathrm{ab}$ initio study," Chemical Physics Letters, vol. 475, no. 1-3, pp. 8285, 2009.

[37] R.-L. Liang, Y. Zhang, and J.-M. Zhang, "Adsorption of oxygen molecular on pristine and defected SiC nanotubes," Applied Surface Science, vol. 257, no. 1, pp. 282-289, 2010.

[38] M. D. Ganji and B. Ahaz, "First principles simulation of molecular oxygen adsorption on $\mathrm{SiC}$ nanotubes," Communications in Theoretical Physics, vol. 53, no. 4, pp. 742-748, 2010.

[39] B. Xiao, J.-X. Zhao, Y.-H. Ding, and C.-C. Sun, "Theoretical studies of chemisorption of $\mathrm{NO}_{2}$ molecules on $\mathrm{SiC}$ nanotube," Surface Science, vol. 604, no. 21-22, pp. 1882-1888, 2010.

[40] R.-L. Liang, Y. Zhang, J.-M. Zhang, and V. Ji, "Adsorption of oxygen atom on the pristine and antisite defected $\mathrm{SiC}$ nanotubes," Physica B, vol. 405, no. 12, pp. 2673-2679, 2010.

[41] S. Jiuxu, Y. Yintang, L. Hongxia, G. Lixin, and Z. Zhiyong, "Electronic transport properties of the armchair silicon carbide nanotube," Journal of Semiconductors, vol. 31, no. 11, Article ID 114003, 3 pages, 2010.

[42] Z. Mahdavifar and M. Haghbayan, "Theoretical investigation of pristine and functionalized AlN and SiC single walled nanotubes as an adsorption candidate for methane," Applied Surface Science, vol. 263, pp. 553-562, 2012.

[43] J. A. Talla, "Ab initio simulations of doped single-walled carbon nanotube sensors," Chemical Physics, vol. 392, no. 1, pp. 71-77, 2012.

[44] A. Soltani, A. A. Peyghan, and Z. Bagher, " $\mathrm{H}_{2} \mathrm{O}_{2}$ adsorption on the BN and SiC nanotubes: a DFT study," Physica E, vol. 48, pp. 176-180, 2013.

[45] M. Andersson, H. Wingbrant, and A. Lloyd Spetz, "Study of the CO response of $\mathrm{SiC}$ based field effect gas sensors," in Proceedings of the 4th IEEE Conference on Sensors, pp. 105-108, November 2005.

[46] B. Ruixin, Z. Jingxiang, and F. Honggang, "Silicon-doping in carbon nanotubes: formation energies, electronic structures, and chemical reactivity," Journal of Molecular Modeling, vol. 19, pp. 1667-1675, 2013.

[47] M. Yang, Y. Zhang, S. Huang, H. Liu, P. Wang, and H. Tian, "Theoretical investigation of $\mathrm{CO}$ adsorption on TM-doped $(\mathrm{MgO})_{12}(\mathrm{TM}=\mathrm{Ni}, \mathrm{Pd}, \mathrm{Pt})$ nanotubes," Applied Surface Science, vol. 258, no. 4, pp. 1429-1436, 2011.

[48] M. E. Grillo, J. W. Andzelm, N. Govind, G. Fitzgerald, and K. B. Stark, "Computational materials science with materials studio applications in catalysis," Lecture Notes in Physics, vol. 642, pp. 207-221, 2004. 

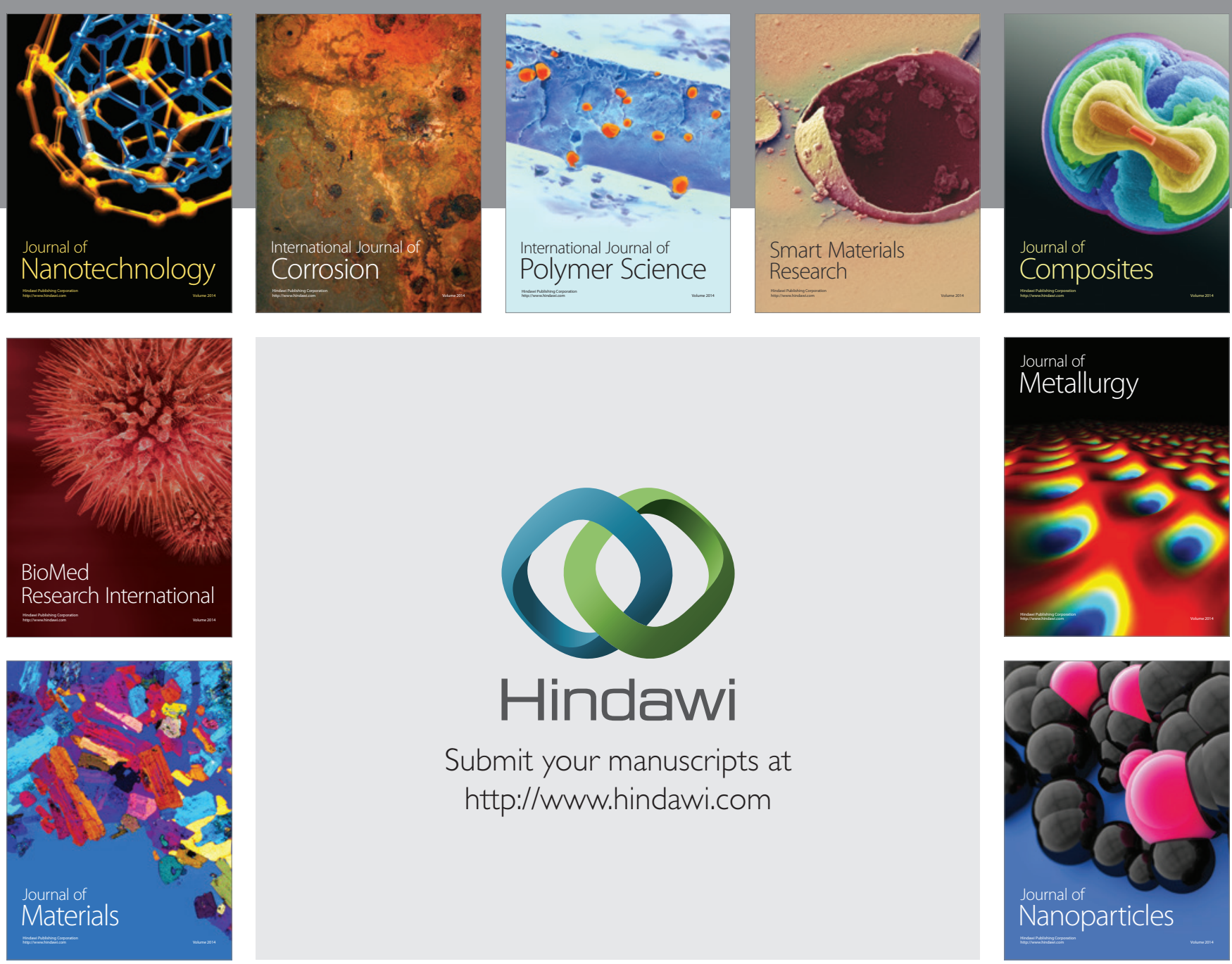

Submit your manuscripts at http://www.hindawi.com
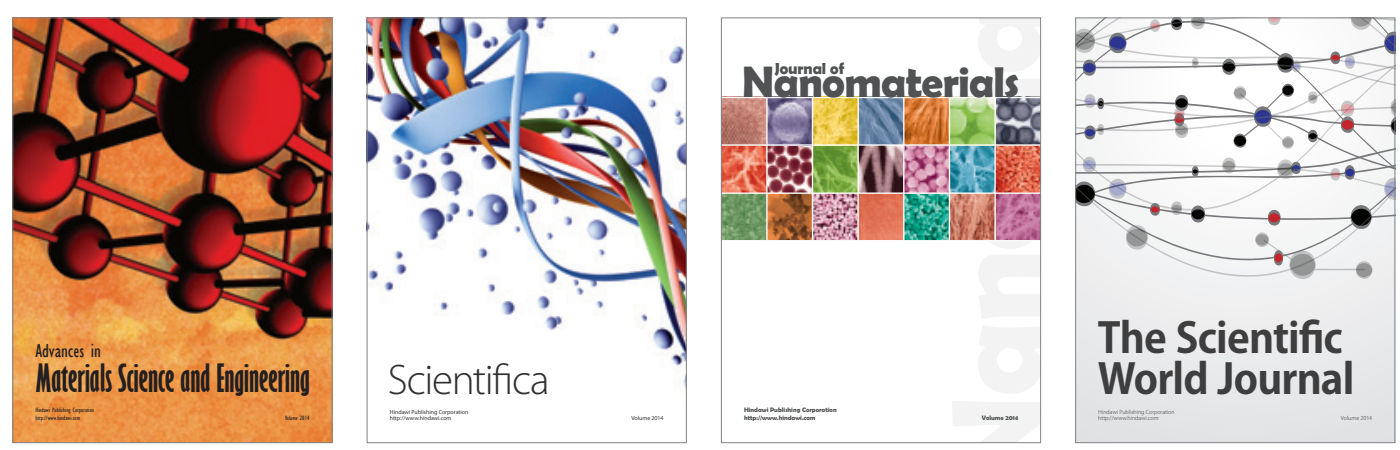

\section{The Scientific World Journal}
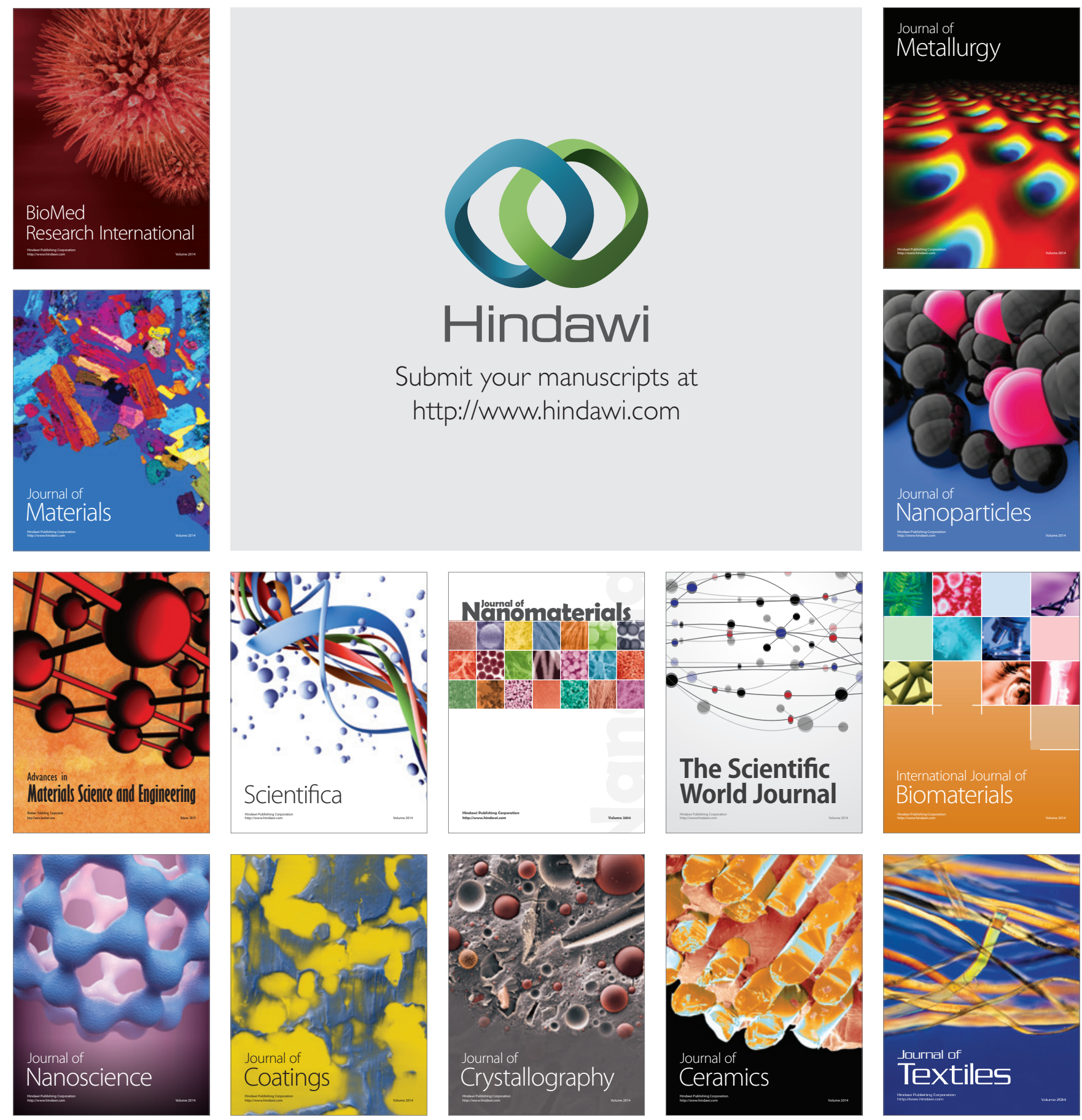